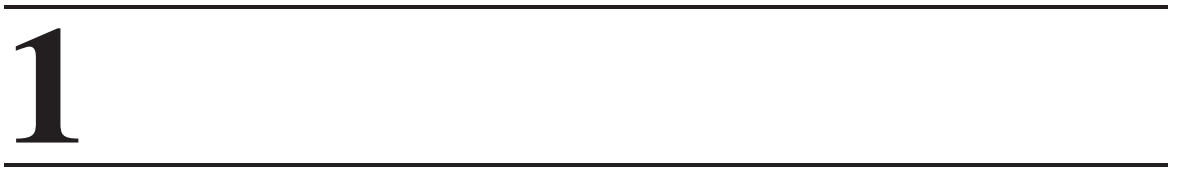

\title{
THE PROBLEM OF ARSENIC CONTAMINATION OF GROUNDWATER
}

\author{
SATINDER AHuja
}

Ahuja Consulting, Calabash, North Carolina

\section{INTRODUCTION}

\section{Nature and Scope of the Problem}

Groundwater contamination by arsenic (As) can occur from a variety of sources, such as pesticides, wood preservatives, glass manufacture, and miscellaneous other arsenic uses. These sources can be monitored and controlled. However, this is not the case with naturally occurring arsenic. The natural content of As in soil is mostly in a range below $10 \mathrm{mg} / \mathrm{kg}$; however, it can cause major havoc when it gets into groundwater. The worst case of this problem was discovered in Bangladesh, where a large number of shallow tube wells (10 to $40 \mathrm{~m}$ ) installed in the 1970s were found in the 1980s to be contaminated with arsenic [1]. Arsenic screening of 4.73 million tube wells showed 1.29 million wells to be above the $50-\mu \mathrm{g} / \mathrm{L}$ level, the acceptable limit in Bangladesh. Since the estimated total number of tube wells in Bangladesh is 8.6 million, it may be concluded that more than 2 million wells in Bangladesh are likely to be contaminated. It has been estimated that as many as 100 million people in Bangladesh are exposed to high levels of arsenic, exceeding the World Health Organization (WHO) standard of $10 \mu \mathrm{g} / \mathrm{L}$, or $10 \mathrm{ppb}$. The maximum contaminant level (MCL) of $10 \mu \mathrm{g} / \mathrm{L}$ for drinking water has been approved by many countries in the world and has been enforced since the beginning of 2006 in the United States. It should be mentioned that the guidelines do not consider different arsenic species, even though it is

Arsenic Contamination of Groundwater: Mechanism, Analysis, and Remediation,

Edited by Satinder Ahuja

Copyright (c) 2008 John Wiley \& Sons, Inc. 
already well established that the toxicity of arsenic can vary enormously with its speciation (see the discussion below).

Skin lesions and cancers related to arsenic were rare and ignored until new evidence emerged from Taiwan in 1977. The serious health effects of arsenic exposure, including lung, liver, and bladder cancer, were confirmed shortly thereafter by studies of exposed populations in Argentina, Chile, and China. In 1984, K. C. Saha and colleagues at the School of Tropical Medicine in Kolkata, India, first attributed lesions observed on the skin of villagers in the state of West Bengal in India to the elevated arsenic content of groundwater drawn from shallow tube wells. As noted in the Preface, the countries affected by elevated arsenic concentrations in groundwater include Argentina, Bangladesh, Cambodia, Canada, Chile, China, Ghana, Hungary, India, Laos, Mexico, Mongolia, Nepal, Pakistan, Poland, Taiwan, Thailand, the UK, the United States, and Vietnam. Figure 1 shows groundwater contamination in the United States; over 31,000 samples analyzed over an almost 30-year period revealed that a large number of states are affected by it. Of various countries affected by this contamination, Bangladesh (see Figure 1 in Chapter 2) and West Bengal are experiencing the most serious groundwater arsenic problem, and the situation in Bangladesh has been described as "the worst mass poisoning in human history." In addition to consumption through drinking water, arsenic can also be taken up via the food chain. Direct consumption of rice irrigated with arsenic-rich waters is a significant source of arsenic exposure in areas such as Bangladesh and other countries where rice is the staple food and provides the main caloric intake.

Arsenic is a semimetal or metalloid that is stable in several oxidation states $(-\mathrm{III}, 0,+\mathrm{III},+\mathrm{V})$, but the $+\mathrm{III}$ and $+\mathrm{V}$ states are the most common in natural systems. Arsenic is a natural constituent of the Earth's crust and ranks twentieth in abundance in relation to other elements. Table 1 shows arsenic concentrations in various environmental media. Arsine(-III), a compound with extremely high toxicity, can be formed under high reducing conditions, but its occurrence in gases emanating from anaerobic environments is relatively rare. Arsenic is a well-known poison with a lethal dose in humans of about $125 \mathrm{mg}$. Most ingested arsenic is excreted from the body through urine, feces, skin, hair, nails, and breath. In cases of excessive intake, some arsenic is deposited in tissues, causing the inhibition of cellular enzyme activities. The relative toxicity of arsenic depends mainly on its chemical form and is dictated in part by the valence state. Trivalent arsenic has a high affinity for thiol groups, as it readily forms kinetically stable bonds to sulfur. Thus, reaction with As(III) induces enzyme inactivation, as thiol groups are important to the functions of many enzymes. Arsenic affects the respiratory system by binding to the vicinal thiols in pyruvate dehydrogenase and 2-oxoglutarate dehydrogenase, and it has also been found to affect the function of glucocorticoid receptors. Pentavalent arsenic has a poor affinity toward thiol groups, resulting in more rapid excretion from the body. However, it is a molecular analog of phosphate and can uncouple mitochondrial oxidative phosphorylation, resulting in failure of the energy metabolism system. The effects 


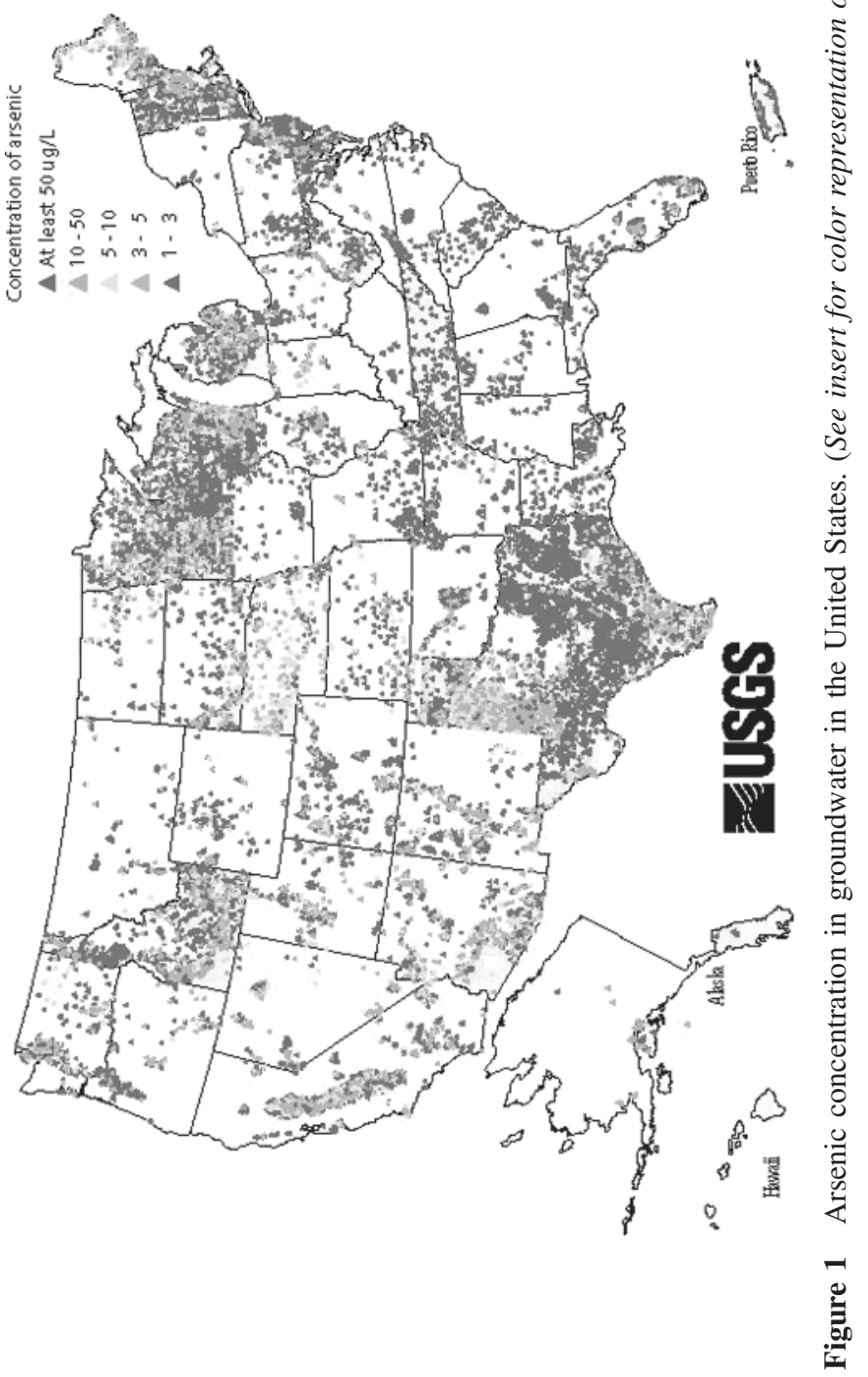


TABLE 1 Arsenic Concentrations in Environmental Media

\begin{tabular}{lc}
\hline Environmental Medium & Arsenic Concentration Range \\
\hline Air $\left(\mathrm{ng} / \mathrm{m}^{3}\right)$ & $1.5-53$ \\
Rain from unpolluted ocean air $[\mu \mathrm{g} / \mathrm{L}(\mathrm{ppb})]$ & 0.019 \\
Rain from terrestrial air $(\mu \mathrm{g} / \mathrm{L})$ & 0.46 \\
Rivers $(\mu \mathrm{g} / \mathrm{L})$ & $0.20-264$ \\
Lakes $(\mu \mathrm{g} / \mathrm{L})$ & $0.38-1000$ \\
Groundwater $($ well $)(\mu \mathrm{g} / \mathrm{L})$ & $1.0-1000$ \\
Seawater $(\mu \mathrm{g} / \mathrm{L})$ & $0.15-6.0$ \\
Soil $(\mathrm{mg} / \mathrm{kg})$ & $0.1-1000$ \\
Stream/river sediment $(\mathrm{mg} / \mathrm{kg})$ & $5.0-4000$ \\
Lake sediment $(\mathrm{mg} / \mathrm{kg})$ & $2.0-300$ \\
Igneous rock $(\mathrm{mg} / \mathrm{kg})$ & $0.3-113$ \\
Metamorphic rock $(\mathrm{mg} / \mathrm{kg})$ & $0.0-143$ \\
Sedimentary rock $(\mathrm{mg} / \mathrm{kg})$ & $0.1-490$ \\
\hline
\end{tabular}

Source: Ref. 2.

of the oxidation state on chronic toxicity are confounded by the redox conversion of $\mathrm{As}(\mathrm{III})$ and $\mathrm{As}(\mathrm{V})$ within human cells and tissues. Methylated arsenicals such as monomethylarsonic acid (MMAA) and dimethyl arsenic (DMAA) are less harmful than inorganic arsenic compounds. Clinical symptoms of arsenicosis may take about six months to two years or more to appear, depending on the quantity of arsenic ingested and the nutritional status and immunity level of the person. Untreated arsenic poisoning results in several stages: for example, various effects on the skin with melanosis and keratosis; dark spots on the chest, back, limbs, and gums; and enlargement of the liver, kidneys, and spleen. Later, patients may develop nephropathy, hepatopathy, gangrene, or cancers of the skin, lung, or bladder.

Arsenicosis now seriously affects the health of many people in Bangladesh, India, China, Nepal, and a number of other countries worldwide. In the United States, nearly $10 \%$ of groundwater resources exceed the MCL. Arsenic toxicity has no known effective treatment, but drinking arsenic-free water can help arsenic-affected people at the preliminary stage of their illness rid themselves of the symptoms of arsenic toxicity. Hence, provision of arsenic-free water is urgently needed for mitigation of arsenic toxicity and the protection of the health and well-being of people living in acute arsenic problem areas in these countries.

A national policy and implementation plan for arsenic mitigation was developed in Bangladesh in 2004, along with protocols for installation of alternative water supply options, disposal of arsenic-rich sludge, diagnosis of arsenicosis cases, and water management. However, provision of alternative arsenic-safe water supplies has thus far reached approximately 4 million citizens, only $2.9 \%$ of the population of Bangladesh. 
In this book we focus primarily on groundwater pollution resulting from natural sources. Until recently it was generally believed that arsenic is released in the soil as a result of weathering of arsenopyrite or other primary sulfide minerals. Currently, it is believed that arsenic pollution of groundwater is a by-product of the microbes that metabolize organic matter, a process that releases arsenic, iron, phosphate, bicarbonate, and other species to groundwater. The precise microbial ecology responsible for arsenic release is still not fully understood and is the subject of further investigation. In an attempt to improve our understanding of this horrific problem, this book has been planned to improve our understanding and to offer some meaningful solutions:

- Nature and scope of the problem (Chapters 1 and 2)

- Mechanism of groundwater contamination (Chapters 3 to 6)

- Low-cost analytical methods and testing kits (Chapters 7 and 8)

- Remediation methods (Chapters 9 to 14 )

- Workable solutions (Chapter 15)

\section{Fate of Arsenic in Irrigation Water and Its Potential Impact on the Food Chain}

The observation that arsenic poisoning in the world's population is not consistent with the level of water intake has raised questions regarding possible pathways of arsenic transfer from groundwater to the human system. Even if an arsenic-safe drinking water supply could be ensured, the same groundwater will continue to be used for irrigation purposes, leaving a risk of soil accumulation of this toxic element and eventual exposure to the food chain through plant uptake and animal consumption. Studies on arsenic uptake by crops indicate that there is great potential for the transfer of groundwater arsenic to crops. Chapter 2 deals with the fate of arsenic in irrigation water and its potential impact on the food chain, particularly as it occurs in Bangladesh and similar environments. Contamination of the irrigation water by arsenic; the retention, release, distribution, and buildup of arsenic in soil, accumulation in various crops that are irrigated with arsenic-rich water, the result of arsenic accumulation in crops and its consequence on dietary intake, and possible remedial measures to combat arsenic accumulation in soils and crops are discussed.

Of the various crops and vegetables analyzed, green leafy vegetables were found to act as arsenic accumulators, with arum (kochu), gourd leaf, Amaranthus, and ipomoea (kalmi) topping the list. Arum, a green vegetable commonly grown and used in almost every part of Bangladesh, seems to be unique in that the concentration of arsenic can be high in every part of the plant. Arsenic in rice seems to vary widely. Speciation of arsenic in Bangladesh rice shows the presence of As(III), DMAV, and $\mathrm{As}(\mathrm{V})$; more than $80 \%$ of the arsenic recovered is in the inorganic form. It has been reported that more than $85 \%$ of the arsenic in rice is bioavailable, compared to only about $28 \%$ of arsenic in leafy vegetables. It is 
thus pertinent to assess the dietary load of arsenic from various food materials otherwise contaminated with arsenic. A person consuming $100 \mathrm{~g}$ [dry weight (DW)] of arum daily with an average arsenic content of $2.2 \mathrm{mg} / \mathrm{kg}, 600 \mathrm{~g}$ (DW) rice with an average arsenic content of $0.1 \mathrm{mg} / \mathrm{kg}$, and $3 \mathrm{~L}$ of water with an average arsenic content of $0.1 \mathrm{mg} / \mathrm{L}$ would ingest $0.56 \mathrm{mg} / \mathrm{day}$, which exceeds the threshold value calculated based on the U.S. Environmental Protection Agency (EPA) model.

\section{MECHANISM OF ARSENIC CONTAMINATION OF WATER}

Until recently it was generally believed that arsenic is released in the soil as a result of weathering of the arsenopyrite or other primary sulfide minerals. Important factors controlling this phenomenon are:

- Moisture (hydrolysis)

- $\mathrm{pH}$

- Temperature

- Solubility

- Redox characteristics of the species

- Reactivity of the species with $\mathrm{CO}_{2} / \mathrm{H}_{2} \mathrm{O}$

It has been reported that weathering of arsenopyrite in the presence of oxygen and water involves oxidation of $\mathrm{S}$ to $\mathrm{SO}_{4}{ }^{2-}$ and $\mathrm{As}(\mathrm{III})$ to $\mathrm{As}(\mathrm{V})$ :

$$
4 \mathrm{FeAsS}+13 \mathrm{O}_{2}+6 \mathrm{H}_{2} \mathrm{O} \leftrightarrow 4 \mathrm{SO}_{4}{ }^{2-}+4 \mathrm{AsO}_{4}{ }^{3-}+4 \mathrm{Fe}^{3+}+12 \mathrm{H}^{+}
$$

Although there are both natural and anthropogenic inputs of arsenic to the environment, elevated arsenic concentrations in groundwater are often due to naturally occurring arsenic deposits. Whereas the average abundance of arsenic in the Earth's crust is between 2 and $5 \mathrm{mg} / \mathrm{kg}$, enrichment in igneous and sedimentary rocks, such as shale and coal deposits, is not uncommon. Arsenic-containing pyrite $(\mathrm{FeS})$ is probably the most common mineral source of arsenic, although it is often found associated with more weathered phases. Mine tailings can contain substantial amounts of arsenic, and the weathering of these deposits can liberate arsenic into the surface water or groundwater, where numerous chemical and biological transformations can take place. Arsenic can also be released directly into the aquatic environment through geothermal water, such as hot springs. Anthropogenic sources of arsenic include pesticide application, coal fly ash, smelting slag, feed additives, semiconductor chips, and arsenic-treated wood, which can cause local water contamination.

In Bangladesh and West Bengal, India, where the problem has received the most attention, the aquifer sediments are derived from weathered materials from the Himalayas. Arsenic typically occurs at concentrations of 2 to $100 \mathrm{ppm}$ in 
these sediments, much of it sorbed onto a variety of mineralogical hosts, including hydrated ferric oxides, phyllosilicates, and sulfides. The mechanism of arsenic release from these sediments has been a topic of intense debate, and both microbial and chemical processes have been invoked. The oxidation of arsenic-rich pyrite has been proposed as one possible mechanism. Other studies have suggested that reductive dissolution of arsenic-rich Fe(III) oxyhydroxides deeper in the aquifer may lead to the release of arsenic into the groundwater. Additional factors that may add further complications to potential arsenic-release mechanisms from sediments include the predicted mobilization of sorbed arsenic by phosphate generated from the intensive use of fertilizers, by carbonate produced via microbial metabolism, or by changes in the sorptive capacity of ferric oxyhydroxides.

A large number of experts from various countries, including Bangladesh and India, who participated in a workshop in Dhaka and in symposia in Atlanta, Georgia [3-5], generally agreed that sedimentary arsenic is being carried downstream to Bangladesh by the Ganges-Padma-Meghna river system. Bacteria have been implicated in the desorption and dissolution of arsenic in the anaerobic, reducing environment in the subsoil. The results from a study conducted in Araihazar, Bangladesh indicate that the accumulation of arsenic in groundwater and sediment release rate in the uppermost $20 \mathrm{~m}$ of the Holocene aquifer appear to be fairly constant within a range of favorable geochemical conditions. This suggests that the groundwater flow regime controls much of the spatial variability of dissolved arsenic concentrations in shallow aquifers; however, this needs to be tested elsewhere in Bangladesh.

\section{Role of Microbes in the Geochemical Behavior of Arsenic in Groundwater Systems}

In Chapter 3 a brief review of high arsenic concentrations in the groundwater and proposed mechanisms for the release of arsenic into groundwater systems is provided, with particular significance to the possible role of metal-reducing bacteria in arsenic mobilization into the shallow aquifers of the Ganges delta. The bacterial effects on arsenic behavior in anoxic sediments and the various interactions between mineral, microbes, and arsenic, which have a significant impact on arsenic mobilization in groundwater systems, are also discussed.

Throughout evolution, microorganisms have developed the ability to survive in almost every environmental condition on Earth. Their metabolism depends on the availability of metal ions to catalyze energy-yielding reactions and synthetic reactions and on their aptitude to protect themselves from toxic amounts of metals by detoxification processes. Furthermore, microorganisms are capable of transforming a variety of elements as a result of (1) assimilatory processes in which an element is taken up into cell biomass, and (2) dissimilatory processes in which transformation results in energy generation or detoxification. Arsenic is called an "essential toxin" because it is required in trace amounts for growth and metabolism of certain microbes but is toxic at high concentrations. However, 
it is now evident that various types of microorganisms gain energy from this toxic element, and subsequently, these reactions have important environmental implications.

Bacterial reduction of $\mathrm{As}(\mathrm{V})$ has been recorded in anoxic sediments, where it proceeds via a dissimilatory process. Dedicated bacteria achieve anaerobic growth using arsenate as a respiratory electron acceptor for the oxidation of organic substrates or $\mathrm{H}_{2}$, forming arsenite quantitatively as the reduction product. The reaction is energetically favorable when coupled with the oxidation of organic matter, because arsenate is electrochemically positive; the As(V)/As(III) oxidation-reduction potential is $+135 \mathrm{mV}$. To date, at least 19 species of organisms are known to respire arsenate anaerobically, and these have been isolated from freshwater sediments, estuaries, hot springs, soda lakes, and gold mines. They are not confined to any particular group of prokaryotes, and they are distributed throughout the bacterial domain. These microbes are collectively referred to as dissimilatory arsenate-reducing prokaryotes (DARPs), and there are other electron acceptors used by these organisms which are strain-specific, including elemental sulfur, selenate, nitrate, nitrite, fumarate, Fe(III), dimethyl sulfoxide, thiosulfate, and trimethyamine oxide. For example, Sulfurospirillum barnesii (formerly strain SES-3), a vibrio-shaped gram-negative bacterium isolated from a selenate-contaminated freshwater marsh in western Nevada, is capable of growing anaerobically using $\mathrm{As}(\mathrm{V})$ as the electron acceptor, and it can also support growth from the reduction of a variety of electron acceptors, including selenate, $\mathrm{Fe}(\mathrm{III})$, nitrate, fumarate, and thiosulfate. The gram-positive sulfate-reducing bacterium Desulfotomaculum auripigmentum, isolated from surface lake sediments in eastern Massachusetts, has been found to reduce both $\mathrm{As}(\mathrm{V})$ and sulfate. DARPs can oxidize a variety of organic and inorganic electron donors, including acetate, citrate, lactate, formate, pyruvate, butyrate, fumarate, malate, succinate, glucose, aromatic hydrogen, and sulfide. Two gram-positive anaerobic bacteria, Bacillus arsenicoselenatis and B. selenitireducens were also isolated from the anoxic, muds of Mono Lake, California. Both grew by dissimilatory reduction of As(V) to As(III), coupled with oxidation of lactate to acetate plus $\mathrm{CO}_{2}$.

\section{Detection of Dissimilatory Arsenate-Respiring Bacteria in North Carolina Groundwater}

Dissimilatory arsenate-reducing bacteria (DARB) are considered to be highly involved in arsenic mobilization in anoxic environments. To determine their contribution to arsenic levels found in underground aquifers, DARB communities in two drinking water wells (labeled D and R) located in western North Carolina were examined by molecular detection methods and enrichment culture techniques (Chapter 4). The genes encoding arsenate respiratory reductase (arrA) were amplified with newly developed polymerase chain reaction (PCR) primers from the DNA extracted from groundwater samples and were used to examine the diversity of DARB communities. The enrichment cultures with groundwater samples were established to measure arsenate reduction activities. The $\operatorname{arr} A$ 
genes detected from both well waters were closely related to the gene found in Geobacter uraniumreducens. A higher diversity of the arrA genes was found in well $\mathrm{R}$, where a higher amount of arsenic was found. In addition, higher arsenate-reducing activities were measured in the $\mathrm{R}$ well water. This might imply that more diverse DARB communities have higher reduction activities, which lead to higher levels of dissolved arsenic found in groundwater. Using molecular and microbial tools, this study demonstrates the significance of DARB in arsenic contamination in the North Carolina underground aquifers.

\section{Biogeochemical Mechanisms of Arsenic Mobilization and Sequestration}

Sediment diagenetic processes are the biogenic and abiotic changes that occur to alter the sediment during and after deposition (see Chapter 5). Sediment diagenesis involves chemical, physical, and biological processes, including (1) deposition, (2) diffusion, (3) reductive dissolution (and other redox changes), and (4) secondary mineral precipitation. Diagenesis is driven primarily by the mineralization of organic carbon and the subsequent changes in redox potential with depth. As the sediments become more reducing, the redox equilibrium of various chemical species in the sediment shifts. However, it is important to recognize that the kinetics of these reactions is variable and sensitive to environmental parameters such as microbial activity. Thus, it is common to observe As(III) and As(V) or $\mathrm{Fe}$ (III) and $\mathrm{Fe}$ (II) co-occurring under a variety of redox conditions because of kinetic factors.

Reductive Fe(III) oxide dissolution is controlled by a complex interplay of many different parameters, such as $\mathrm{pH}$, redox state, mineralogy, biological activity, and solution chemistry. Biologically mediated reduction depends strongly on the bacterial consortia present in the sediments, as well as substrate availability (e.g., organic carbon) and $\mathrm{Fe}$ oxide crystallinity. The rate of dissolution can, in turn, affect the mineral transformation products, which have the potential to sequester arsenic in more crystalline lattice structures, or the release of arsenic to pore waters as surface binding sites are lost.

A case study illustrates how arsenic partitioning between the solid and dissolved phases can be affected simultaneously by arsenic redox cycling, sediment diagenesis, and pore water composition. Ultimately, the mobility of arsenic in surface and groundwater systems is determined by (1) the arsenic redox state, (2) associations with the solid phase, (3) transformation of the solid phase during diagenesis, and (4) pore water composition, which can also change as a result of diagenetic processes. Many of these parameters are driven by microbial processes. This interplay of biogeochemical mechanisms makes understanding the processes responsible for arsenic mobilization in the environment inevitably complex.

\section{Geomicrobiology of Iron and Arsenic in Anoxic Sediments}

Microbially mediated reduction of assemblages comprising arsenic sorbed to ferric oxyhydroxides is gaining consensus as the dominant mechanism for the 
mobilization of arsenic into groundwater. For example, a recent microcosm-based study provided the first direct evidence for the role of indigenous metal-reducing bacteria in the formation of toxic mobile As(III) in sediments from the Ganges delta (see Chapter 6). This study showed that the addition of acetate to anaerobic sediments, as a proxy for organic matter and a potential electron donor for metal reduction, resulted in stimulation of microbial reduction of $\mathrm{Fe}(\mathrm{III})$, followed by $\mathrm{As}(\mathrm{V})$ reduction and the release of As(III). Microbial communities responsible for metal reduction and As(III) mobilization in the stimulated anaerobic sediment were analyzed using molecular (PCR) and cultivation-dependent techniques. Both approaches confirmed an increase in numbers of metal-reducing bacteria, principally Geobacter species. However, subsequent studies have suggested that most Geobacter strains in culture do not possess the arrA genes required to support the reduction of sorbed $\mathrm{As}(\mathrm{V})$ and mobilization of $\mathrm{As}(\mathrm{III})$. Indeed, in strains lacking the biochemical machinery for $\mathrm{As}(\mathrm{V})$ reduction, $\mathrm{Fe}(\mathrm{II})$ minerals formed during respiration on $\mathrm{Fe}(\mathrm{III})$ have proved to be potent sorbants for arsenic present in the microbial cultures, preventing mobilization of arsenic during active iron reduction. However, the genomes of at least two Geobacter species (G. unraniumreducens and G. lovleyi) do contain arrA genes, and interestingly, genes affiliated with the G. unraniumreducens and G. lovleyi arrA gene sequences have been identified recently in Cambodian sediments stimulated for iron and arsenate reduction by heavy $\left({ }^{13} \mathrm{C}\right.$-labeled) acetate using a stable isotope-probing technique. Indeed, the type strain of G. unraniumreducens has recently been shown to reduce soluble and sorbed $\mathrm{As}(\mathrm{V})$, resulting in mobilization of $\mathrm{As}(\mathrm{III})$ in the latter case. Thus, some Geobacter species may play a role in arsenate release from sediments. However, other well-known arsenate-reducing bacteria, including Sulfurospirillum species, have also been detected in ${ }^{13} \mathrm{C}$-amended Cambodian sediments and hot spots associated with arsenic release in sediments from West Bengal. Although the precise mechanism of arsenic mobilization in Southeast Asian aquifers remains to be identified, the role of $\mathrm{As}(\mathrm{V})$-respiring bacteria in the process is gaining support. Indeed, recent studies with Shewanella sp. ANA-3 and sediment collected from the Haiwee Reservoir (Olancha, California) have suggested that such processes could be widespread, but not necessarily driven by $\mathrm{As}(\mathrm{V})$ reduction, following exhaustion of all bioavailable $\mathrm{Fe}(\mathrm{III})$. In this study, arsenate reduction started before Fe(III) reduction and ceased after 40 to 60 hours. During part of the experiment, arsenate and Fe(III) were reduced simultaneously.

\section{ANALYTICAL METHODS}

It is not difficult to determine arsenic at $10 \mathrm{ppb}$ or an even lower level in water. A number of methods can be used for determining arsenic in water at the ppb level:

- Flame atomic absorption spectrometry

- Graphite furnace atomic absorption spectrometry 
- Inductively coupled plasma-mass spectrometry

- Atomic fluorescence spectrometry

- Neutron activation analysis

- Differential pulse polarography

Very low detection limits for arsenic down to $0.0006 \mu \mathrm{g} / \mathrm{L}$ can be obtained with inductively coupled plasma mass spectrometry (ICP-MS). The speciation of arsenic requires separations based on solvent extraction, chromatography, and selective hydride generation. High-performance liquid chromatography (HPLC) coupled with ICP-MS is currently the best technique available for the determination of inorganic and organic species of arsenic; however, the cost of the instrumentation is prohibitive. For underdeveloped countries confronting this problem, the development of reliable, low-cost instrumentation and reliable field test kits would be very desirable (see the discussion below).

\section{Development of Low-Cost Measurement Technologies for On-Site Arsenic Determination}

Hydride generation (HG) has been known for many decades and has the advantage that arsenic may be determined by a relatively inexpensive atomic absorption spectrometer or an even cheaper atomic fluorescence spectrometer (AFS) at single-digit $\mu \mathrm{g} / \mathrm{L}$ concentrations (see Chapter 7). Its generation is prone to inference from other matrix components, so every "new" matrix can represent a new analytical problem. In this technique, arsenic compounds are converted to volatile derivatives by reaction with a hydride transfer reagent, usually tetrahydroborate III (also known as borohydride), whose sodium and potassium salts are relatively stable in aqueous alkalis. HG can be quite effective as an interface between high-performance liquid chromatographic separation and element-specific detection. In fact, it is possible to get the same performance from HG-AFS as from ICP-MS. Therefore, as the former detector represents a significant saving in both capital and operational costs over the latter, there is considerable interest in this "niche" use of AFS. The disadvantage of any method in which an atomic spectrometry instrument is involved is that the procedure has to be carried out in a laboratory setting in which appropriate supplies of electricity, gas, power, and sometimes cooling water are available.

Accurate, fast measurement of arsenic in the field remains a technical challenge. Even though the technological advances in a variety of instruments have met with varying success, the central goal of developing field assays that reliably and reproducibly quantify arsenic has not yet been achieved. The exquisite selectivity of the hydride generation process is very tempting as an integral pretreatment stage, but always comes with the associated issues of safety unless all of the arsine generated ends up bound to a solid surface somewhere in the apparatus. However, it will be quite some time before the Gutzeit method is obsolete. 
There are clearly many prospects for the further development of chemical measurement technologies for the determination of arsenic in environmental waters down to single-digit $\mu \mathrm{g} / \mathrm{L}$ concentrations. In this scenario, techniques such as atomic fluorescence spectrometry are good candidates for such a "lab" facility. The quartz crystal microbalance, a device whose interface is more robust than an electrode for stripping voltammetry, also holds promise, especially as the measurement incorporates an inherent preconcentration step (the accumulation of arsenic at the surface of the oscillating crystal).

\section{Reliability of Test Kits}

In a comprehensive study (see Chapter 8) using three field kits (Merckoquant, NIPSOM, and GPL), more than 290 wells were tested against reference methods. At arsenic concentrations below $50 \mu \mathrm{g} / \mathrm{L}$, the false positive results were acceptably low: 9.2\% (NIPSOM) and 6.5\% (GPL). In the range between 50 and 100 $\mu \mathrm{g} / \mathrm{L}$, false positives increased to $35 \%$ and $18 \%$, respectively. As a result, using the NIPSOM kit, $33 \%$ of the unsafe tube wells were colored green (i.e., safe). The false negative results reported between 50 and $100 \mu \mathrm{g} / \mathrm{L}$ were $57 \%$ and $68 \%$, which means that up to two-thirds of the wells painted red were safe. Above 100 $\mu \mathrm{g} / \mathrm{L}$, the percentage of false negatives was still considerable (26\% for NIPSOM and $17 \%$ for GPL). The mislabeling of $45 \%$ of the wells is unacceptable but cannot be explained easily by possible variability of arsenic concentration, a lack of quality assurance/quality control, or operator error. This study clearly demonstrates the need for a stringent testing procedure to generate reliable data and the need to develop more reliable analytical systems that would make costly retesting unnecessary. Emphasis should be given to new developments of electrochemical methods and their potential to form the basis of a "new generation" of field kits that satisfy all requirements for reliable arsenic detection in the field.

Two main approaches are used at present for the on-site analysis of arsenic. By far, the most widely used systems are those based on a colorimetric principle. These systems require few reagents, are supposedly easy to use, and give results that should be straightforward. The second approach is based on electroanalysis and on the possibility of reducing or oxidizing arsenic species. Although more difficult to operate, the detection limits obtained with such devices can be much lower than those obtained by colorimetry. The EPA supports an environmental technology verification (ETV) program to facilitate the implementation of innovative new technologies for environmental monitoring. The ETV works in partnership with recognized standards and testing organizations, with vendors and developers, and with stakeholders for potential buyers. The ETV tested several commercially available kits in July 2002 and added four more in August 2003 under field conditions with trained and untrained operators [6]. An assessment of the new generation of field testing kits is provided in Table 2 of Chapter 8.

In contrast to colorimetric field tests kits, which are selective for arsenic only, voltammetric systems can be tuned to detect other metals simultaneously. For example, at a gold electrode, metals such as $\mathrm{Cu}, \mathrm{Hg}, \mathrm{Zn}, \mathrm{Mn}$, or $\mathrm{Sb}$ can be detected 
along with arsenic. For instance, antimony has been shown to modulate the toxicity of arsenic [7] and was found in samples containing high levels of arsenic [8]; $35 \%$ of the arsenic-contaminated groundwater samples from Bangladesh also contained levels of manganese above the WHO value of 500 ppb [9]. Knowledge of the concentrations of other metals brings insights into the toxicity of the sample and is the basis for efficient removal technologies. Field systems should therefore be as selective as possible.

The performance of field testing kits for arsenic is unsatisfactory overall, although the new generation of kits have become much more reliable. The report of false negative and false positive results of over $30 \%$ is not unusual, although the latest seem encouraging, and more reliable measurements can be done in the field. However, these studies were using a water standard of $50 \mu \mathrm{g} / \mathrm{L}$ as a decisive concentration. If the new WHO guideline of $10 \mu \mathrm{g} / \mathrm{L}$ is adopted as a decision-making criterion, the sensitivity of most arsenic testing kits based on colorimetric methods will not be sufficient. This is particularly the case for kits that are battery powered and also for electronic systems. Although some reports surprisingly suggest that in some cases untrained operators produce more reliable results, the training aspect of the operator should not be underestimated. Voltammetric sensors should be ideally suited for on-site analysis of arsenic. However, the need for a chemical reduction step seems to be the major problem, limiting potential applications both in the field and in sample throughput. Systems using voltammetric reduction of arsenate are probably easier to implement for on-site analysis, although the SafeGuard system developed by TraceDetect Inc. has remarkable performance rates. Potential problems in the voltammetric determination of arsenic are numerous because of the sample matrix effect. To be highly efficient for on-site analysis with unqualified operators, these voltammetric systems should therefore be as sensitive as possible to allow dilution of the original sample. For such purposes, the use of microelectrodes is preferred. In addition, specifically designed software and hardware are required to guide the user through the simple actions required to make the analytical system more accessible to unqualified operators. Although promising results have been obtained using voltammetric systems, more work is needed to develop methods toward these arsenic species. The most promising development in direct arsenic speciation is by electrochemical detectors, but they still have to be tested in the field.

\section{REMEDIATION OF ARSENIC-CONTAMINATED WATER}

A large number of approaches have been investigated for removing arsenic from drinking water. Several useful reviews of the techniques for removing arsenic from water supplies have been published [10-13]. Existing and emerging arsenic removal technologies include:

- Coagulation with ferric chloride or alum

- Sorption on activated alumina 
- Sorption on iron oxide-coated sand particles

- Granulated iron oxide particles

- Polymeric ligand exchange

- Nanomagnetite particles

- Sand with zero-valent iron

- Hybrid cation-exchange resins

- Hybrid anion-exchange resins

- Polymeric anion exchange

- Reverse osmosis

Reverse osmosis is essentially a nonselective physical process for excluding ions with a semipermeable membrane The basic chemistry for the rest of the processes includes either or both of the following interactions: (1) $\operatorname{As}(\mathrm{V})$ oxyanions are negatively charged in the near-neutral $\mathrm{pH}$ range and therefore can undergo coulombic or ion-exchange types of interactions; and (2) $\mathrm{As}(\mathrm{V})$ and As(III) species, being fairly strong ligands or Lewis bases, are capable of donating lone pairs of electrons. They participate in Lewis acid-base interactions and often show high sorption affinity toward solid surfaces that have Lewis acid properties.

\section{Flocculation of Arsenic with the Mucilage of Opuntia ficus-indica}

The design of a benign and sustainable water purification technology based on natural products is gaining interest because of the inherently renewable character, low cost, and nontoxicity. The use of mucilage, derived from nopal cactus, Opuntia ficus-indica, provides a reliable technology to treat drinking water supplies that have been contaminated with particulates and toxic metals (Chapter 9). The long-term goal is to deploy the optimized design in rural and underdeveloped communities in Mexico, where drinking water supplies are contaminated with toxic metals, the nopal cactus is readily available and amenable to sustainable agriculture, and where access to conventional technologies is limited. This work shows how cactus mucilage is extracted from the nopal cactus and used as a flocculant to remove particulates and heavy metals from drinking water. Mucilage efficiency to reduce arsenic and particulates from drinking water has been determined by light scattering, jar tests, atomic absorption, and hydride generation-atomic fluorescence spectroscopy. Comparisons against a synthetic flocculant [i.e., aluminum sulfate, alum, $\mathrm{Al}_{2}\left(\mathrm{SO}_{4}\right)_{3}$ ] show the high efficiency of that cactus mucilage to separate particulates and arsenic from drinking water. These flocculation studies prove that mucilage is a much faster flocculating agent than alum, with the efficiency increasing with mucilage concentration. Jar tests reveal that lower concentrations of mucilage provide the optimal effectiveness for supernatant clarity, an important factor in determining the potability of water. This work has established a systematic approach for providing clean water that can be expanded to communities of other underdeveloped or even developed countries 
with similar pollution problems. This natural material has shown the potential for development of a worldwide technology that is innovative, environmentally benign, and cost-effective. The mucilage from $O$. ficus-indica is a better flocculant than aluminum sulfate in all three of its extracted forms (GE, NE, and CE) and could be used by low-income Latin American communities for settling suspended solids in turbid drinking water-storage containers. The use of mucilage is also appropriate for removal of total arsenic in contaminated drinking water and owes its flocculation abilities to its chemical structure, consisting of $\mathrm{C}-\mathrm{O}$ functionality. Further investigation is required to review the mucilage-selective removal of arsenic based on speciation as well as the feasibility of implementing this technology in a distributable or easy-to-assemble filter form for small-scale household removal. The possibility of introducing an indigenous material as an improver of quality of life and health to concerned residents is attractive from a cultural sensitivity and sustainability standpoint.

\section{Arsenic Removal by Adsorptive Media}

Rapid, inexpensive tests are needed to predict the arsenic adsorption capacity of adsorptive media to help communities select the most appropriate technology for meeting compliance with the new arsenic MCL, $10 \mu \mathrm{g} / \mathrm{L}$. A main goal of this project is to evaluate alternative methods to predict pilot- and full-scale performance from laboratory studies. Prediction of arsenic removal from a packed column is very challenging (Chapter 10). Three innovative adsorptive media that have the potential to reduce the costs of arsenic removal from drinking water were selected. The arsenic removal performance of these different adsorptive media under constant ambient flow conditions was compared using a combination of static (batch) and dynamic flow tests. These included batch sorption isotherm and kinetic sorption studies, rapid small-scale column tests (RSSCTs), and a

pilot test at a domestic water supply well. The media studied included a granular ferric oxyhyroxide (E33), a granular titanium oxyhydroxide (MetSorb), and an ion-exchange resin impregnated with iron oxide nanoparticles (ArsenX). They exhibited contrasting physical and chemical properties. The E33 media gave the best performance, based on volume of water treated until breakthrough at the arsenic MCL (10 ppb) and full capacity at media exhaustion. The relative arsenic sorption capacity of the three media could be predicted from batch sorption studies and RSSCT column results. The Klinkenberg analytical solution gave good semiquantitative descriptions of arsenic breakthrough curves and pore water profiles in the pilot tests, based on parameters obtained in the RSSCT studies. The model is potentially useful for scaling up adsorptive media performance to any reasonable size from the data obtained in laboratory studies.

Arsenic is removed in fixed-bed filtration via adsorption, the physical and chemical attachment of the adsorbate (arsenic) to the surface of the adsorbent media grains. The removal capacity and effectiveness of the arsenic removal media are dependent on a number of physical and chemical factors. Chemical factors include the strength of the chemical bond between the arsenic and the 
adsorbent, the kinetics of the adsorption reaction, the concentrations of ions competing for sorption sites, the concentration of arsenic in the feed water, and the $\mathrm{pH}$ of the feed water. Physical (transport) factors include the effective surface area, which is a function of the accessibility of the porosity of the media grains; steric factors affecting the accessibility of the pore sites by arsenic ions; and the time available for arsenic ions to migrate to pore sites. The latter property is related to the flow rate of the feed water that conveys the arsenic into the bed of adsorbent media. In this study the consistency among capacity estimates made by batch and dynamic methods are compared, and their relevance to full-scale performance is evaluated.

\section{Remediation of Bangladesh Drinking Water Using Iron Oxide-Coated Coal Ash}

In Chapter 11 a process is described for removing arsenic from water based on using fine particles of coal bottom ash that have been coated with iron oxide. This technique is called ARUBA (arsenic removal using bottom ash). The bottom ash is the ash left at the bottom of a coal-fired boiler after the combustible matter in coal has been burned off. A study successfully demonstrated the ability of this technique to reduce arsenic concentrations to below the Bangladesh standard of 50 ppb in six of the eight samples of Bangladesh groundwater collected. The water was collected from two geographically distinct areas of Bangladesh and across six different villages. For water samples from the two remaining wells, numbers 2 and 8 , where the final concentration measured with ICP-MS was above $50 \mathrm{ppb}$, a larger dose of coal bottom ash coated with iron oxide would have certainly lowered the concentration to below $50 \mathrm{ppb}$. The study also demonstrated the feasibility in some samples of reducing arsenic concentrations in the water to below the WHO standard of $10 \mathrm{ppb}$.

\section{Development of a Simple Arsenic Filter for Groundwater in Bangladesh}

Chapter 12 covers the development and deployment of a water filter called SONO filter based on especially made composite iron matrix for the purification of groundwater to safe potable water. The filtered water meets $\mathrm{WHO}$ and Bangladesh standards, has no breakthrough, and works without any chemical treatment (before or after), without regeneration, and without producing toxic waste. It costs about $\$ 40$, lasts for five years, and produces 20 to $30 \mathrm{~L} / \mathrm{h}$ for the daily drinking and cooking needs of one to two families. Approved by the Bangladesh government, about 35,000 SONO filters are deployed all over Bangladesh and continue to provide more than 1 billion liters of safe drinking water. This innovation was also recognized by the National Academy of Engineering's Grainger Challenge Prize for Sustainability, with the highest award for its affordability, reliability, ease of maintenance, social acceptability, and environmental friendliness. The device meets or exceeds the local government's guidelines for arsenic removal. The filter is designed with Bangladesh village people in mind. It does not require any special maintenance other than replacement of 
the upper sand layers when the apparent flow rate decreases. Experiments show that the flow rate may decrease 20 to $30 \%$ per year if groundwater has a high iron content $(>5 \mathrm{mg} / \mathrm{L})$ because of the formation and deposition of natural HFO in sand layers. The sand layers (about an inch thick) can be removed, washed, and reused, or replaced with new sand. The presence of soluble iron and the formation of HFO (hydrous ferric oxide) precipitate are also common problems with other filtration technologies.

The use of tube wells to extract groundwater was initiated to provide drinking surface water that is not contaminated with pathogenic bacteria. However, pathogenic bacteria can still be found in drinking water because of unhygienic handling practices, and also in many shallow tube wells, possibly located near unsanitary latrines and ponds. To investigate the issue of bacterial growth in these filters, a Bangladesh nongovernmental organization called the Village Education Resource Center (VERC) recently tested 193 SONO filters at 61 locations in one of the remotest fields, Sitakundu in Bangladesh. The report shows that of the 264 tests, 248 were found to have 0 ttc (thermotolerance coliforms)/100 mL and 16 had $2 \mathrm{ttc} / 100 \mathrm{~mL}$. Pouring $5 \mathrm{~L}$ of hot water in each bucket every month has been shown to kill pathogenic bacteria and eliminate coliform bacteria. This protocol can be followed once a week in areas where coliform counts are high. There are no records of diarrhea or waterborne diseases from drinking SONO-filtered water, and it appears that the filtration system does not foster pathogenic bacteria on its own.

Except for basic training in hygiene, no special skill is required to maintain the filter. The maintenance process requires about 20 to 30 minutes. Because this filter has no breakthrough, the active medium does not require any processing, such as backwashing or chemical regeneration. The filter will produce potable water for at least five years (the time span of our continuing test results). The actual filter life span was determined by the life span of the six experimental filters running in the field. Except for manufacturing defects, mechanical damage due to mishandling, transportation, and natural disasters (flooding), none of the filters have shown MCL breakthrough to date. Presently, at $\$ 35$ to $\$ 40$ for five years (equivalent to one month's income of a village laborer in Bangladesh), SONO is one of the most affordable water filters in Bangladesh.

\section{Community-Based Wellhead Arsenic Removal Units}

In many remote villages in West Bengal, arsenic-contaminated groundwater remains the only feasible source of drinking water. Cost-effective arsenic removal technology is a minimum necessity to provide safe drinking water. The groundwater is otherwise free of other contaminants and safe for drinking. Over 150 wellhead arsenic removal units, containing activated alumina as the adsorbent, are currently being operated by local villagers in this state in India, which borders Bangladesh. The units are maintained and run by the beneficiaries. In regular operation the units require no chemical addition, $\mathrm{pH}$ adjustment, or electricity (Chapter 13). Each unit serves approximately 250 to 350 families living within a short distance of the unit, and the flow rate is modest, approximately $10 \mathrm{~L} / \mathrm{min}$. 
Arsenite $[\mathrm{As}(\mathrm{III})]$ and arsenate $[\mathrm{As}(\mathrm{V})]$ from the groundwater are effectively removed to render it safe for drinking and cooking. Regenerability and durability of the adsorbent allows a low-cost, sustainable solution for the widespread arsenic poisoning in this area. After regeneration, the spent regenerants, containing high concentrations of arsenic, are converted to a small-volume sludge that is stored under oxidizing conditions, to prevent future arsenic leaching. This process offers a superior economic advantage with regard to treatment and management of dangerous treatment residuals compared to conventional adsorbent-based processes where regeneration and reuse are not practiced. With conventional processes, disposal of huge amounts of media in landfills leach out dangerous concentrations of arsenic. A global scheme for the overall process of arsenic removal, including the management of treatment residues, has been provided. Input to the process is groundwater contaminated with arsenic and caustic soda and acid for regeneration, whereas the outputs are only treated drinking water and neutralized brine solution. Thus, besides being most appropriate for rural sections of the affected area in terms of ease of use and economics, the technology also offers considerable ecological sustainability.

From the data for 150 running units, it is estimated that the total volume of water treated by a unit in one year, on average, is about 8000 bed volumes (i.e., $800,000 \mathrm{~L}$ ), so the cost of water per $1000 \mathrm{~L}$ is equal to $\$ 0.85$. The estimated amount of arsenic-safe water used for a family of six for drinking and cooking purposes in a month at the rate of $5 \mathrm{~L}$ per capita per day is $900 \mathrm{~L}$. The water tariff for a family of six for one month is around $\$ 0.75$, or 30 Indian rupees at the time of this writing. While regeneration helps reduce the volume of the sludge about 150 -fold, reusability of the sorbent media helps decrease the cost of the treated water significantly.

\section{Water Supply Technologies for Arsenic Mitigation}

Development of water supply systems to avoid arsenic-contaminated water sources, and the removal of arsenic to acceptable levels, are two options for a safe water supply (Chapter 14). Totally arsenic-free water is not available in nature; hence the only workable option to avoid arsenic is to develop water supply systems based on sources that have very low rates of dissolved arsenic. Rainwater, well-aerated surface water, and groundwater in very shallow as well as deep aquifers are well-known arsenic-safe sources of water. Rainwater has very low arsenic levels, often undetectable by conventional detection methods and measurement techniques. The arsenic content of most surface water sources ranges from less than $1 \mu \mathrm{g} / \mathrm{L}$ to $2 \mu \mathrm{g} / \mathrm{L}$. Very shallow groundwater replenished by rainwater or surface water and relatively old deep aquifers have arsenic contents within acceptable levels.

The technologies for producing drinking water using sources known to have a low arsenic content include:

- Treatment of surface water by slow sand filtration, conventional coagulation-sedimentation-filtration, and disinfection. Rivers, lakes, and ponds are 
the main sources of surface water, and the degree of treatment required varies with the level and type of impurities present in water.

- Dug wells/ring wells or very shallow tube wells to abstract low-arsenic groundwater from very shallow aquifers.

- Deep tube wells to collect arsenic-safe water from deep protected aquifers.

- A rainwater harvesting system (RWHS) to collect, store, and use rainwater before it joins the surface water and groundwater.

A wide range of technologies based on arsenic-safe water sources is available for the water supply at low cost, but the performance of the technologies varies widely, depending on the quality of raw water. Community participation in the operation and maintenance of small surface water-based technologies and RWHS is not encouraging. The performance of medium-size to large systems that can support a full-time operator is comparatively better. Tube well technologies are the preferred option for people in arsenic-affected areas, but tube wells are not always successful in producing arsenic-safe water at all locations.

Arsenic removal technologies have improved significantly during the last few years, but reliable, cost-effective, and sustainable treatment technologies are yet to be identified and developed further to meet requirements. All treatment technologies concentrate arsenic at some stage of treatment in different media. Large-scale use of an arsenic removal system may generate significant quantities of arsenic-rich treatment wastes, and indiscriminate disposal of these wastes may lead to environmental pollution. Safe disposal of arsenic-rich media is a concern that needs to be addressed.

\section{Solutions Available for Providing Arsenic-Free Water}

Regarding the mechanism of arsenic contamination, there is reasonable agreement within the scientific community that research should continue (Chapter 15). Economical and reliable analytical methods, including field kits, need to be developed to help solve this problem. The Implementation Plan for Arsenic Mitigation of Bangladesh issued in 2004 states that while the research to devise appropriate options continues, the arsenic mitigation programs must promote the following options: improved dug wells; surface water treatment, including pond sand filters and large-scale surface water treatment; deep hand tube wells, rainwater harvesting, arsenic removal technology, and piped water supply systems. In the implementation plan, preference is given to pond sand filters and improved dug wells while government's role in rainwater harvesting will be limited to promotional activities only. In case of arsenic removal technologies, the implementation plan recommends waiting until the issues relating to the safety of these technologies, in terms of chemical and biological water quality, along with issues relating to the disposal of liquid and solid wastes, are better understood.

Based on input from various participants in the Dhaka workshop [3] and the Atlanta symposia [5], the following recommendations appear to be logical for Bangladesh and the other Southeast Asian countries that are most severely 
affected by this problem. Piped surface water should be intermediate to long-term goals and should be given the desired priority. This will require total commitment from the local government and the funding agencies that deem this a desirable option. Along these lines, other surface water options, such as rainwater harvesting, sand water filters, and dug wells, should be tapped as much as is reasonably possible. The next best option is safe tube wells. More than likely they would be deep tube wells. It is important to assure that they are located properly and do not contain other contaminants that can add to the arsenic problem. Furthermore, they should be installed properly such that surface contaminants cannot get into them. The arsenic removal filtration systems can work on a small scale; however, their reliability initially or over a period of time remains an issue. Other contaminants in water can affect the systems' performance. Low-price reliable test kits are needed that can address this issue. There is a need to identify reliable filters that can be scaled up for larger communities. In this way, both maintenance and reliability issues can be addressed. The education and training of local scientists and technicians need to be encouraged so that the local people can address these problems themselves. There is a need for more analytical scientists, instrumentation, and testing laboratories. Consumers of contaminated water need to be better educated so they do not continue to drink contaminated water because of their reluctance to switch wells or to take other steps to purify water.

The use of some of these options depends on local conditions. It is important to remember that local scientists and others are the final arbiters as to what is best for a given area.

\section{REFERENCES}

1. S. Ahuja and J. Malin. International Conference on Chemistry for Water, Paris, June 21-23, 2004.

2. EPA-815-R-00-023, U.S. EPA, Washington, D.C., December 2000.

3. S. Ahuja. International Workshop on Arsenic Contamination and Safe Water, Dhaka, Bangladesh, Dec. 11-13, 2005.

4. S. Ahuja and J. Malin. Chem. Int., 2006, 28(3):14-17.

5. S. Ahuja. American Chemical Society Meeting, Atlanta, GA, Mar. 26-30, 2006.

6. ETV Joint Verification Statement (U.S. EPA/Batelle). http://www.epa.gov/etv/ verifications/vcenter1-21.html.

7. T. Gebel. Mutation research. Genet. Toxicol. Environ. Mutagen., 1998, 412:213.

8. S. H. Frisbie. et al. Environ. Health Perspect., 2002, 110:1147.

9. BGS/DPHE (British geological survey/Department of Public Health Engineering, Bangladesh). Arsenic Contamination of Groundwater in Bangladesh, vol. 1, Summary. D. G. Kinniburgh and P. L. Smedley, Eds. British Geological Survey Report WC/00/19. http://www.bgs.ac.uk/arsenic/Bangladesh/Reports/Vol1Summary.pdf.

10. M. Bissen and F. Frimmel. Arsenic-a review: I. Occurrence, toxicity, speciation, mobility. Acta Hydrochim. Hydrobiol ., 2003, 31:9-18. 
11. M. Bissen and F. Frimmel. Arsenic-a review. II. Oxidation of arsenic and its removal in water treatment. Acta Hydrochim. Hydrobiol., 2003, 31:97-107.

12. K.-S. Ng, Z. Ujang, and P. Le-Clech. Arsenic removal technologies for drinking water treatment. Rev. Environ. Sci. Biotechnol., 2004, 3:43-53.

13. B. Daus, R. Wennrich, and H. Weiss. Sorption materials for arsenic removal from water: a comparative study. Water Res., 2005, 38:2948-2954. 
